\title{
Face-to-face talk to support computer- mediated discussion in a primary school literacy practice
}

\author{
Judith Kleine Staarman
}

\begin{abstract}
In this study, Dutch primary school children used a computer-mediated discussion forum to discuss the concept of horror stories. In such discussion forums children often write their contributions individually. This paper presents an ongoing empirical study in which the contributions to an electronic discussion forum from children working individually were compared to contributions from children working in dyads. Preliminary results indicated that children working in dyads around the computer wrote more contributions to the computer-mediated discussion and were more attentive to the collaborative process, than children who wrote their contributions individually.
\end{abstract}

\section{Introduction}

The use of Information and Communication Technology (ICT) has become common practice in primary schools nowadays. At the same time, there has been a growing emphasis on learning in more social contexts, such as collaborative learning. These innovations and the subsequent introduction of new types of electronic texts and communication, have changed literacy practices in particular. Electronic texts, such as web pages and electronic presentations, often contain hypertext and audio-visual elements while people are also using e-mail, computer chat, or instant messaging systems to communicate. Through these innovations, the concept of literacy has changed to literacy as a social practice, in which being able to read and search for information in different domains of knowledge as well as communicating ideas and knowledge using a variety of (electronic) media has become important.

Computer-Supported Collaborative Learning (CSCL) is considered as one of the most promising recent innovations to improve the quality of learning and instruction with technology (Lehtinen, Hakkarainen, Lipponen, Rahikainen and Muukkonen, 1999). One way of implementing CSCL in classrooms is by means of computer-mediated communication (CMC) systems, such as discussion forums. Teachers can have a variety of reasons to be interested in using electronic discussion forums in their classrooms. Because of the relationship of these forums with the current emphasis on collaborative learning, they are considered an easy way of integrating both collaborative learning and ICT in classrooms. Because these kinds of software tools are usually open-ended environments, and may therefore be used with all kinds of content, they do not necessarily imply a radical change of the curricular content. On the other hand, the open-ended discussion forums can become catalysts for change, especially when the software is used by the students to initiate new topics for learning and to discuss new collaborative activities (Guzdial and Turns, 2000). Moreover, a text-based discussion forum, in which children's contributions are stored for future reference, makes it possible for larger groups of children to work together, even if only a few computers are available.

The use of a text-based communication medium allows participants to share multiple perspectives or ideas about a particular subject or issue. Text-based communication is more explicit than face-to-face communication and the time delay and permanence allow for reflection on earlier stated information and to 'think before talking' (Veerman, Andriessen and Kanselaar, 2000). However, the quality of the discussion in a CMC system also depends on the type of task, features of the learning environment, the prior knowledge of the students, and the support of the teacher, among other factors. Besides, children in primary education might not feel the need to reflect on others' ideas and thoughts and therefore, just thinking before talking might not be enough to trigger a more elaborate discussion. So, one way to elicit reflection on one's own contributions and on the contributions from others might be through combining the advantages of faceto-face interaction in dyads with the advantages of computer-mediated interaction. The aim of this research project is to study computer-mediated interactions of children in the context of literacy practices in the primary classroom. In this paper I will use some of the data gathered in this study, to discuss if and how face-to-face interaction in dyads around the computer supports the development and quality of discussion through a CMC system.

\section{Learning together in a CSCL environment}

Computer-supported collaborative learning refers to specific practices in which children are actively and 
collaboratively engaged in creating knowledge, and where collaboration is taking place through a computer network (Lehtinen et al., 1999). Implementing CSCL in classrooms implies a new approach to learning, one that emphasises a more active and constructive role for learners, in which learning is regarded as a process of interaction and negotiation with others (Van der Linden, Erkens, Schmidt and Renshaw, 2000). Moreover, CSCL implies collaborative learning, which can be considered as the co-construction of meaning through interaction with others, and joint commitment to a shared goal. This means that participants must try to establish common knowledge while engaging in a coordinated effort to perform a task together (Littleton and Häkkinen, 1999).

\section{Interaction in small groups}

If learning is considered as a process of interaction and co-construction, literacy practices can be seen as social practices in which children construct meaning, articulate questions, and share ideas in order to foster their thinking and concept development. Within these literacy practices, language is one of the most important mediating tools for the sharing of knowledge and provision of intellectual support (Mercer, Wegerif and Dawes, 1999). However, there is little consensus about which characteristics of language are most important and beneficial for the learning process. Some researchers consider conflict and argumentation to be crucial while others stress the collaborative construction of meaning through the articulation of the participants' thoughts (Crook, 1999). Yet others focus on specific speech acts in talk that can lead to productive interaction, such as predicting, asking higher-order questions or giving elaborated answers (King, 1994; Webb, 1989). But even though many researchers focus on these kinds of cognitive aspects of collaborative interaction, the aspects which make the interaction into a true collaborative effort are often disregarded. Although individual participants may express many utterances that in themselves could be considered as beneficial for the learning process, sometimes there is an apparent lack of collaboration between the same participants. Some indicators for collaborative aspects of interaction are the presence of close links between succeeding utterances, asking questions for further expansion of a contribution, and attentiveness to the social needs of others (Barnes and Todd, 1977).

\section{Software to support interaction}

Many different software tools have been developed to support and structure interaction in CSCL practices, using various modes of computer-mediated communication and different pedagogical methods. Some software tools have a build-in support for synchronous communication, for example using a chat client or an instant messaging function, whereas other types of software are designed with asynchronous communication tools. Asynchronous communication can be established using e-mail or through a discussion forum, in which discussions can develop over hours, days or longer while participants are reading, reflecting, and responding to others. These discussion forums are usually unstructured learning environments, which means that they are without pre-defined topics or tasks and the teacher or the students themselves decide on the topic of the discussion. This enables the students to take more responsibility for their own learning process. The discussion takes place by participants writing mainly text-based contributions and responding to the contributions of others. The software tool typically keeps track of the development of the discussion and visualises which contributions are responses to others. Generally, all the input is stored in a communal database for future reference and to facilitate the sharing of knowledge and ideas.

\section{Asynchronous, computer-mediated interaction}

The key issue in computer-mediated learning environments is that participants share their knowledge and ideas in order to learn from each other. The effectiveness of this knowledge-sharing process largely depends on the interaction of the students participating in the learning environment. In this sense, the nature of computer-mediated interaction might not be very different than that of face-to-face interaction.

However, asynchronous computer-mediated interaction in particular, is a different process from faceto-face interaction. Because of its text-based communication mode, contradictions or conflicts between students' opinions may be revealed more explicitly. Additionally, interacting in asynchronous CSCL environments could lead to a more egalitarian style of communication, since students are not aware of one another's physical appearance (Wegerif, 1998). Moreover, in contrast to face-to-face interaction, students interacting through a computer network do not have to rely on attention-getting and conversational skills. Therefore, especially children who are too inhibited to 'speak out' in classroom discussions might benefit from the absence of social presence in CSCL environments.

Apart from these benefits, the possible loss of social relationships in these environments may also have an adverse effect on learning. The absence of non-verbal cues and the feeling of relative anonymity could lead to less efficient communication and even rude behaviour. This feeling of anonymity might also lead to the idea of being left out, and students can feel insecure about their contributions if everyone else can read them as well. Thus for computer-mediated interaction to be collaborative and to lead to knowledge building, it 
seems necessary not only to state your ideas and knowledge explicitly, but also to express social or affective statements explicitly, in order to create and maintain a collaborative and safe atmosphere.

In this study, the idea was that by working in dyads around the computer, the children might, through quick, informal responses, be able to combine the specific advantages of speech with the advantages of writing, namely taking time to consider work in depth and using the opportunity to revise notes before contributing to the communal database (Mercer, 2000). Another hypothesis was that children might be less hesitant to give their opinion if they were able to check their ideas with someone sitting next to them first, before presenting them to the rest of the class. Moreover, talking together in dyads might elicit more reflection on the contributions in the discussion forum than when the children worked individually. Subsequently, these ideas led to the following research question: does face-to-face talk enhance the development and quality of computer-mediated discussion in terms of the content of the discussion and the collaborative process?

\section{Method}

The design of the project is based on the idea of interactive research, which implies a close partnership between the researchers and the primary school teachers in whose classrooms the research is carried out (Mercer, 1996). In this study, the teacher developed the tasks together with the researchers, according to the schools' curriculum goals for literacy. Additionally, the teacher was involved in the selection of the participants and the formation of the dyads.

\section{The learning environment}

The software used in this project is called Knowledge Forum (KF). It has been developed by researchers from the Ontario Institute for Studies in Education (OISE), specifically to support knowledge building through computer-mediated interaction (Scardamalia and Bereiter, 1992). Knowledge Forum is a communal database in which children's contributions (notes) are saved so the children can read each other's contributions and respond to them by writing a 'build-on note'. As in other discussion forums, in KF there is no predefined content. However, in KF there is integrated support for categorising the written contributions in order to scaffold the students' argumentation and reasoning processes (see Figure 1).

Moreover, unlike other discussion forums where the contributions are generally threaded in a linear structure, in KF the contributions to the database are represented in a non-hierarchical, web-like structure (see Figure 2). By representing the contributions in this non-hierarchical way, it might become more natural and easier for children to respond to earlier written contributions. When they log in to KF, they immediately see which notes they have read and which notes are new additions to the database. In KF the discussion spaces in which children work, are called 'views'. These views are restricted discussion spaces, comparable with different web pages. Each view usually contains contributions on a specific topic or from a certain group of students.

\section{School and students}

The 28 participants in this study (14 boys and 14 girls, age 11-12) were Sixth-Grade students of a modern, rather large Dutch primary school. The school is situated in a city housing estate in the south-east of the Netherlands and has approximately 380 , generally middle-class, students. The school had been involved in a government-initiated programme to promote computers in education, through which they had recently acquired 30 networked computers. These computers were situated in two different areas of the school, one dedicated computer room with 22 computers, and one smaller area with eight computers.

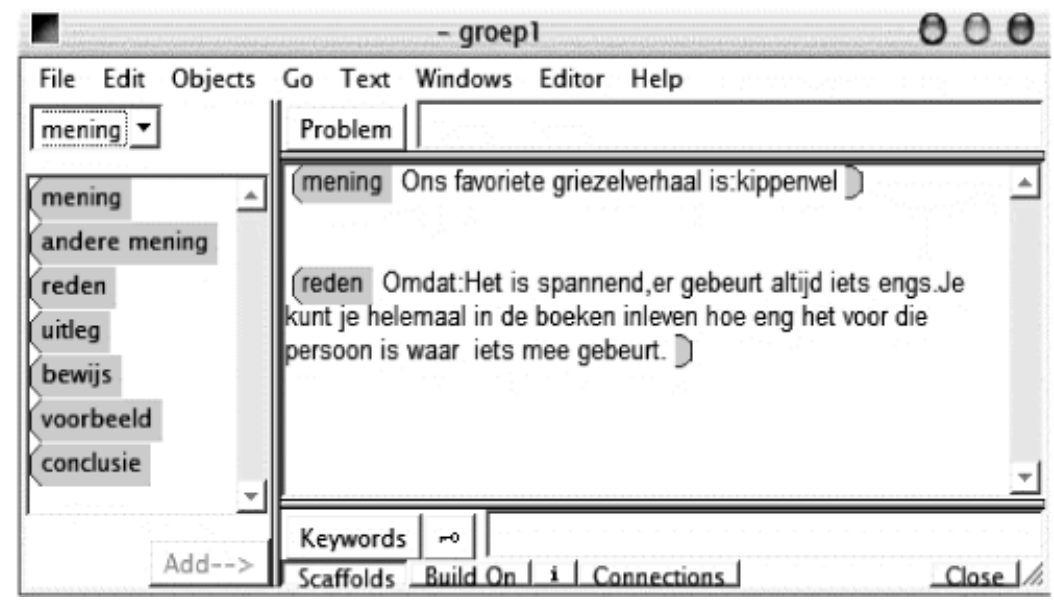

Figure 1. A Knowledge Forum note with the scaffold support in the left panel 


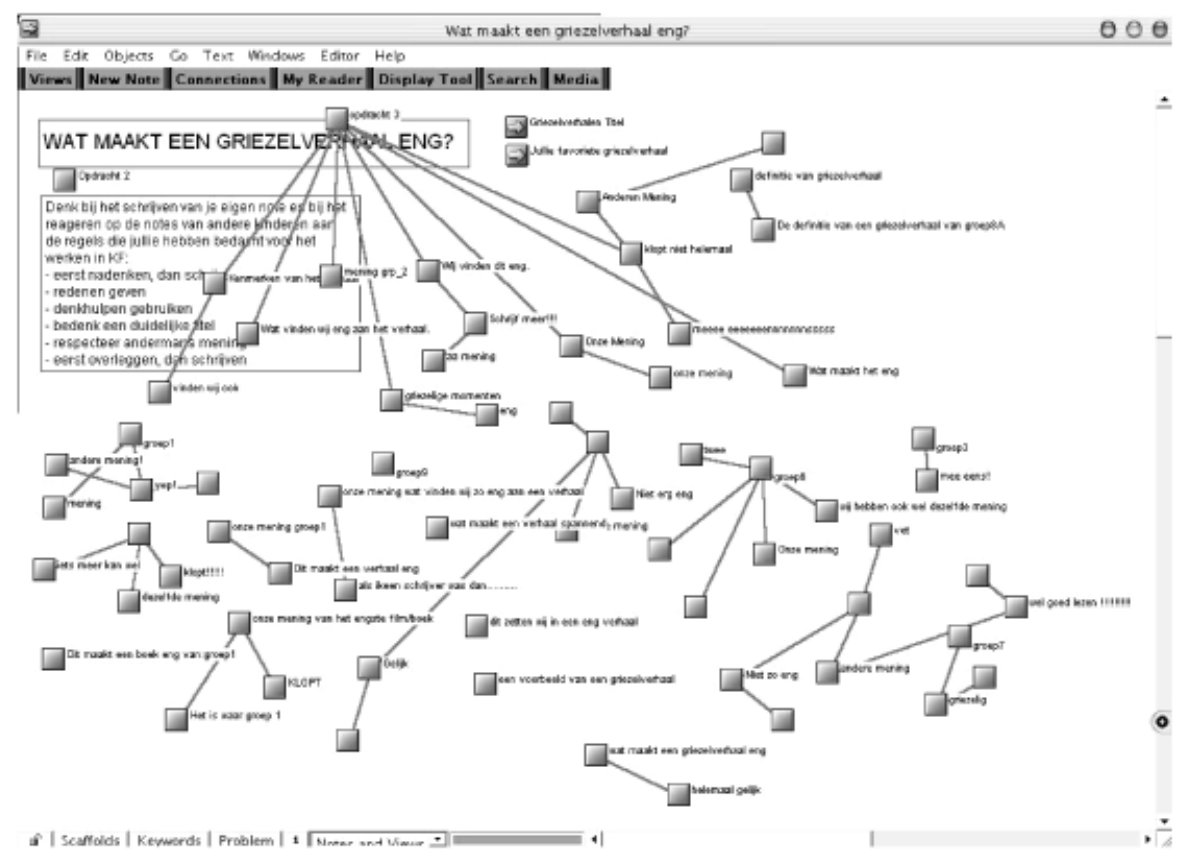

Figure 2. Non-hierarchical, web-like discussion structure in Knowledge Forum

Although the children were accustomed to smallgroup work, they used the computers mainly for individual work. At the time, the teacher was disappointed with the software that was available (predominately of the drill and practice type) and with the apparent lack of integration of ICT with the rest of her classroom practice. Yet she became very enthusiastic about using Knowledge Forum since she felt that KF could provide new ways to integrate ICT with the rest of the curriculum content and might support collaborative learning. Before this project started, the children had been using KF for several weeks to familiarise with the software. Even though an English language version of Knowledge Forum was installed, the children had no problems in using it, and after one lesson they confidently explored and used all the features available to them.

\section{The task: discussion about horror stories}

The topic of this project was 'horror stories' and the final task for the children was to write a horror story themselves. We used this topic because the children had indicated that adventure and horror stories were the ones they preferred to read. Since these kinds of stories were also the ones they read most often, we assumed that most pupils could think of examples of horror stories while discussing this topic in KF. Before writing their own story, the children used KF to discuss the concept of horror stories. The purpose of these discussions was to familiarise them with the genre of horror stories, to create common knowledge regarding this topic, and to make them aware of the different strategies used by authors to make a story scary and exciting to read.
The project's duration was eight weeks, with one 45-minute lesson per week. The first four lessons were spent discussing the concept of horror stories and the last four were used to write the story. For the purpose of this paper, only the data collected during the discussion stage of the project has been used.

\section{The research project}

To be able to compare the computer-mediated discussions of children who worked individually and children who worked in dyads, the children involved were divided into two groups, the first consisting of nine dyads and the second of ten children working individually. The children in the dyads were paired, heterogeneously, based on the assumption that the ability levels of the two children should be somewhat different to generate better discussion. However, at the same time we did not want the differences between the ability levels to be too high, since we wanted the language of the children to be attuned to each other. So, each dyad consisted of either one low and one averageachieving child or one average and one high-achieving child. A nationally standardised test for reading comprehension and a teacher assessment of oral skills were used to provide evidence for this pairing. The teacher made sure no problematic dyads had been created, and the dyads remained the same throughout the project. The children who worked individually used different KF 'views' from those used by the children who worked in dyads, and for each lesson, a new view was created. As a result, after the discussion stage, eight KF views, containing a total of 154 written contributions were analysed. Additionally, the face-to-face 
Table 1: The number of notes written in KF

\begin{tabular}{lccc}
\hline$N$ & $\begin{array}{l}\text { Total } \\
\text { number of } \\
\text { written } \\
\text { notes }\end{array}$ & $\begin{array}{l}\text { Average } \\
\text { number of } \\
\text { written } \\
\text { notes per } \\
\text { user/dyad }\end{array}$ \\
& & & 10.5 \\
Dyads & 9 & 95 & 6.3
\end{tabular}

talk of four focal dyads (two dyads in each lesson) was recorded on minidisk and analysed.

\section{Results and discussion}

The research question was: 'Does face-to-face talk enhance development and quality of the computermediated discussion in terms of the content of the discussion and the collaborative process?'. Table 1 demonstrates that children who worked in dyads wrote nearly twice as many contributions as the children who worked individually, even though the same amount of time was spent working in KF.

A first analysis of the written notes revealed that the children who worked in dyads showed more awareness of the task and of the strategies they had to use, such as argumentation strategies. To illustrate this, I present three representative sequences of CMC contributions. Sequences 1 and 2 provide illustrations of the KF discussions of dyads, and Sequence 3 shows the $\mathrm{KF}$ discussions of individual children. All sequences are translated from Dutch and correspond as much as possible to the actual words used by the children. For the purpose of this paper, the notes are shown threaded, with the first note above the build-on notes. The children were discussing their favourite horror stories and in the task it was stated that they should not only give their opinions, but they had to give reasons for them as well.

The first sequence shows two connected notes in which one dyad (Group 6) mentioned that their favourite story is one of the 'Goosebumps' books (Stine, 1996) and gave a reason for their opinion. Group 7 responded to this contribution by writing a build-on note in which they asked for a better explanation. The underlined words (opinion, reason, and conclusion) indicate the use of the built-in scaffold support of KF. The children had to choose the supports they considered appropriate for their note.

\section{Sequence 1}

1. by: group6

2. opinion: our favourite horror story is the book Goosebumps: The Girl Who Cried Monster
3. reason: because the story is very exciting and you can really imagine yourself in it

4. by: group7

5. conclusion: It is OK like this but it's a pity that your reason is so short you could have written for example why the story is so exciting and which other books he has written and what the name of the author is

In the task, it was stated that the children had to give reasons for their opinions. This sequence shows that Group 6 used the scaffold supports to indicate that they were giving their opinion about what they thought was their favourite horror story, and the reason support to point out their reason for this opinion [line 3]. The sequence also shows that the children were critically aware of the other groups and of the given task. After briefly stating that they think the contribution of Group 6 is OK, Group 7 challenged the contribution and pointed out which elements they thought would be appropriate for an evaluation of a horror story [line 5]. The reason that Group 6 did not respond to this challenge might be due to the fact that Group 7 used the scaffold support 'conclusion' to start their contribution and the criticism is stated as a fact, whereas if Group 7 had chosen a support such as 'we would like to know' or 'opinion', then this perhaps could have triggered another, perhaps more elaborate response.

\section{Sequence 2}

1. by: group 5

2. Opinion: The scariest story we know is: Mars Attacks

3. Reason: Because there are sometimes deadly parts in it and then you begin to find it scary

4. Opinion: We think the scariest things of horror stories are: monsters, aliens and murders

5. Likewise

6. by: group 2

7. It's a pretty scary film but couldn't you write a bit more?

8. by: group 5

9. That is all there is to say about it!!!!

10. Same opinion

11. by: group 1

12. Conclusion: That's right; we have written something just like you please respond to our opinion. We think murders are quite scary and unexpected things as well

13. by: group7

14. Explanation: You could have written a bit more in it. And you could have given more explanations, such as you could write down a piece in which something scary is happening

15. Not very scary

16. by: group 4

17. We don't think Mars Attacks is very scary it's more humorous but sometimes it is also a bit exciting and gross 
In this longer sequence of notes, Group 5 wrote the first note, responding to the question: what is the scariest story you know and what are scary aspects of horror stories in general? Since they did not know any scary books, they chose a film as their favourite. They also used scaffold supports to motivate their arguments [lines 2, 3 and 4]. As in Sequence 1, the groups are critically aware of the task and are not afraid to point this out. In this sequence, two different strategies are used to criticise the contribution of another group, namely by asking a direct question [line 7] and by pointing out different ideas [line 14]. Nevertheless, Group 2's question is not a higher-order question (King, 1994) which might be the reason that it does not elicit a more elaborated response from Group 5. After reading this, Group 7 tried a different strategy; they explained what they thought Group 5 could have done in order to answer the question in a better way. Group 7 used the same strategy as in Sequence 1, although in Sequence 2 they used the scaffold support 'explanation' instead of 'conclusion'. But just as in Sequence 1, their contribution does not generate a response, which might be due to the fact that the contribution is of a closed, rather than inviting nature.

Additionally, in this sequence, in two instances the groups explicitly stated their agreement with the written statement from the group they responded to [lines 7 and 12]. According to Barnes and Todd (1977), formal expressions of agreement are indicators of the level of 'collaborativeness' of the discussion. In general, the dyads showed much more explicit agreement in their contributions than the children who worked individually. The dyads explicitly agreed with other groups in 25 cases (in a total of 93 notes), whereas the individual children only explicitly agreed with each other in four cases (in a total of 63 notes).

The KF discussions of the dyads contrasted with the discussions of the children who worked individually, in that the dyads showed more awareness to the other groups by responding to the content of contributions that others had written, through asking for further explanations and explicitly stating their agreement. The following sequence (Sequence 3) is a typical sequence of notes from children who worked individually.

\section{Sequence 3}

1. by: Eliane

2. Opinion: My favourite horror story is: Goosebumps

3. Reason: Because you always want to finish the book in one go. And I like a bit of excitement and creepiness.

4. Goosebumps is for little children

5. by: michael

6. Opinion: I think goosebumps is not scary at all since it's written for little children

7. for michael!!!!!!
8. by: beracha

9. hey michael

10. Opinion: goosebumps is not for little children at all you don't even dare to read it

11. beracha

12. for michael from

13. by: eliane

14. hello mike!

15. I think Goosebumps is not for little children at all because they wouldn't understand it anyway! But that's your opinion.

16. mikey

17. by: alaina

18. Yes that's right and they may not even be allowed/dare to read it!!! But they probably don't even want to!!!

Sequence 3 shows that the children who worked individually used their own names to log into KF, in contrast to the dyads, who logged in using their group numbers. Probably as a consequence of this, they also often addressed their contributions to each other in the title of the note [lines 7, 9, 12, and 16]. By doing so, and thus revealing their identity, the children seemed to focus more on giving a response to a particular person, whereas the dyads seemed to be more focused on the content of the notes; i.e. on what constitutes a horror story and what should be included in the contributions according to the given task. Barnes and Todd (1977) consider naming to be one of the indicators of the collaborativeness of a discussion. However, in CMC interaction it would seem that this shifts the focus of the contributions from awareness to the strategies and the content of the contributions, to merely replying to each other in a chat-like manner. This would support the claim made by Wegerif, that interacting in asynchronous CSCL environments, where there is a perceived lack of social appearance (in this case through the use of group names instead of their own names), could lead to a more egalitarian style of communication (Wegerif, 1998).

Furthermore, an additional analysis of the face-to-face discussion within the dyads gave some indication of how the face-to-face talk contributed to the quality of the discussion. The following sequence of face-to-face talk in a dyad (Sequence 4) illustrates the discussion of the content of their note before contributing it to the KF database.

Sequence 4: Face-to-face talk of a dyad about scary elements of horror stories

$\mathrm{A}=$ Anne

$\mathrm{S}=$ Susanne

(...) denotes inaudible speech

Underlined indicates emphatic speech

1. S: We should do my theory (...) 
2. A: evidence, example

3. S: ehm, conclusion. Opinion, opinion

4. A: our story

5. S: OK, we

6. A: we (starts typing)

7. S: We think a book becomes scary when

8. A: there are murders in it?

9. S: No, what makes a horror story scary?

10. A: We think a book is scary (starts typing)

11. S: when

12. A: a murder

13. S: a murder is

14. A: committed

15. S: is committed or when someone

16. A: is being chased (...)

17. A: We think a book becomes scary when someone commits a murder and when someone is being chased, etcetera

18. A: ehm, the scariest

19. S: Yes, but we shouldn't just do the scariest

20. A: Scary, what's scary about it is

21. S: Is that there are, like

22. A: The scariest is that there are like

23. S: That there is suspense in the story

24. 1: They make it

25. S: Oh yes, I know it. They make it scary

26. A: Yes

27. S: By waiting a long time, and then, suddenly

28. A: something shows up

29. S: Yes

30. A: Something shows up (starts typing)

31. A: (...) They make the story scary by waiting a long time and then suddenly something

32. S: Something happens, which makes it very thrilling

33. A: thrilling

34. S: Would that be enough?

35. A: Shouldn't thrilling be with two l's?

36. S: Yes

37. A: Irritating spelling. We think that a book

38. S: We think that a book becomes scary when someone commits a murder or when somebody is being chased, etcetera. The scariest is that it is so thrilling (...) They make the story scary by waiting a long time and then suddenly something happens, which makes it very thrilling

In this sequence, the children are discussing the content of their note in response to the given task, which was to describe what they considered scary aspects of horror stories. The children started discussing which scaffold support they should include [lines 1-3] before brainstorming about different scary features of horror stories. In the meantime they typed their ideas in KF and from time to time they recapitulated and reflected on what was written so far [lines 17 and 31-34]. This sequence also shows that the reason that the dyads wrote nearly twice as many notes as children working individually was not just because the dyads were merely taking turns. It illustrates that the 'thinking before talking' feature of CMC discussions could be elicited by the face-to-face interaction in the dyads. Several indicators of collaborative face-to-face interaction can be seen in this sequence, such as the presence of close links between succeeding utterances and the frequent extension of preceding remarks (Barnes and Todd, 1977), which in this case led to an elaborated contribution to the KF discussion.

\section{Concluding remarks}

The research question that guided this paper was: does face-to-face talk enhance the development and quality of computer-mediated discussion in terms of the content of the discussion and the collaborative process? Even though the work presented in this paper is a first analysis of research in progress, the results give some indication that computer-mediated discussion in KF might benefit from the face-to-face talk of children working in dyads around the computer. From the analysis of the written notes, it appears that children who worked individually in KF hardly reflected on different ideas about horror stories. It seemed that in this group, the 'thinking for talking' property of text-based computer-mediated discussion only accounted for thinking about one's own contribution and scarcely for thinking about the contributions of others. The children who worked in dyads contributed more to the computer-mediated discussion and their contributions were of a more collaborative nature than the contributions from children working individually.

These results suggest that working in dyads around the computer might be a way to improve the development of a computer-mediated discussion and help to sustain the discussion. However, some limitations should be taken into account when interpreting the results of this study. First, further analysis of the data is needed to find out which specific aspects of the face-to-face interaction led to better contributions in the discussion forum and if, and in what way the collaborative process in computer-mediated discussions was supported by the face-to-face talk. For example, additional content analysis of both the faceto-face talk and the CMC discussion might reveal whether the face-to-face talk was eliciting a better understanding of a horror story in the written contributions. Second, the task that was used did not provide a coherent shared goal and therefore might not have elicited as much discussion as would a task where the children perceive a clear, shared goal. However, the idea was to centralise the ideas of children regarding the topic of horror stories and to let them create common knowledge on this subject, rather than to impose predefined elements and definitions of horror stories on them. Finally, in follow-up studies we should perhaps compare dyads using their own name to identify themselves with dyads who are using a more neutral way of identifying themselves in an 
asynchronous discussion forum, since it would seem interesting to explore further the social aspects of asynchronous discussion in primary education.

\section{References}

BARNES, D. and TODD, F. (1977) Communication and Learning in Small Groups. London: Routledge and Kegan Paul.

CROOK, C. (1999) 'Computers in the Community of Classrooms' in K. Littleton and P. Light (Eds.) Learning with Computers: Analysing Productive Interaction. London: Routledge.

GUZDIAL, M. and TURNS, J. (2000) Effective Discussion through a Computer-Mediated Anchored Forum. Journal of the Learning Sciences 9, pp. 437-469.

KING, A. (1994) Guiding Knowledge Construction in the Classroom: Effects of Teaching Children how to Question and how to Explain American Educational Research Journal 31, pp. 338-368.

LEHTINEN, E., HAKKARAINEN, K., LIPPONEN, L., RAHIKAINEN, M. and MUUKKONEN, H. (1999) Computer Supported Collaborative Learning: A Review. Nijmegen: Department of Educational Sciences, University of Nijmegen.

LITTLETON, K. and HÄKKINEN, P. (1999) 'Learning Together: Understanding the Processes of Computer-based Collaborative Learning' in P. Dillenbourg (Ed.) Collaborative Learning: Cognitive and Computational Approaches. Oxford: Pergamon.

MERCER, N. (1996) The Quality of Talk in Children's Collaborative Activity in the Classroom. Learning and Instruction 6, pp. 359-377.

MERCER, N. (2000) Words and Minds: How we use Language to Think Together. London: Routledge.

MERCER, N., WEGERIF, R. and DAWES, L. (1999) Children's Talk and the Development of Reasoning in the Classroom, British Educational Research Journal 25, pp. 95-111.
SCARDAMALIA, M. and BEREITER, C. (1992) 'An Architecture for Collaborative Knowledge Building' in E. DeCorte, M. C. Linn, H. Mandl and L. Verschaffel (Eds.) Computer-Based Learning Environments and Problem Solving. Berlin/Heidelberg: Springer Verlag. STINE, R. L. (1996) Kippenvel: Eet Smakelijk [Goosebumps: The Girl Who Cried Monster]. Alkmaar, The Netherlands: Kluitman.

VAN DER LINDEN, J., ERKENS, G., SCHMIDT, H. and RENSHAW, P. (2000) ‘Collaborative Learning' in: R. J. Simons, J. Van der Linden and T. Duffy (Eds.) New Learning. Dordrecht, The Netherlands: Kluwer Academic Publishers.

VEERMAN, A. L., ANDRIESSEN, J. E. B. and KANSELAAR, G. (2000) Learning through Synchronous Electronic Discussion. Computers \& Education 34, pp. 269-290.

WEBB, N. M. (1989) Peer Interaction and Learning in Small Groups. International Journal of Educational Research 13, pp. 21-39.

WEGERIF, R. (1998) The Social Dimension of Asynchronous Learning Networks. Journal of Asynchronous Learning Networks 2, pp. 34-49.

CONTACT THE AUTHOR:

Judith Kleine Staarman, University of Nijmegen, Faculty of Social Sciences, Department of Pedagogical Sciences and Education, Montessorilaan 3, 6525 HR Nijmegen, The Netherlands. e-mail: j.kleinestaarman@ @ed.kun.nl 